ReVista de la Escuela de Ciencias de la educación, año 15, nRo. 14, vol. 2, JULIO A diCiembre de 2019. PÁGINAS 71-80. ISSN 1851-6297 (DESDE DIECIEMBRE DE 2006 A DICIEMBRE DE 2017). ISSN 2362-3349 (EN LíNEA). TRAS LAS HUELLAS DEL ARTE INFANTIL. MARGARITA MARIA ZAPATA GUTIÉRREZ.

\title{
TRAS LAS HUELLAS DEL ARTE INFANTIL
}

\author{
Margarita María Zapata Gutiérrez \\ Universidad de Baja California, México \\ mmaria.zapata@udea.edu.co
}

Recibido: 7/09/2018 Aceptado: 8/01/2019

\section{Resumen}

Tras las huellas del arte infantil, presenta un análisis estético en donde a partir de un horizonte de antropologización, se rescata el arte infantil como aisthesis. Desde esta perspectiva, en el primer apartado se examina el dibujo como lenguaje semiótico cuyos signos, índices y registros, remiten a un proceder estético que instaura sentido en el mismo acto de crear grafías, rescatando la indexicalidad del dibujo infantil, y su sentido como lenguaje autónomo del lenguaje. En el segundo apartado, pasando al análisis de la obra infantil desde la Estética Simbólica, el arte de los niños como lenguaje simbólico, remite a un significante no necesariamente consciente; presentando algo que no está, materializado a través de la pintura, como vehículo de inscripción simbólica. En el último apartado, se opta por un análisis del arte infantil desde la Estética Expandida, en donde a partir de la aisthesis, el arte es de todo y para todos, incluyendo el arte de los niños y jóvenes.

Palabras clave: Educación - Estética - Infantiles - Dibujos - Niño.

\section{Abstract}

In the footsteps of children's art, he presents an aesthetic analysis where, from an anthropologis horizon, where children's art is rescued as aisthesis; From this perspective, in the first section examines drawing as a semiotic language whose signs, indexes and registers, refer to an aesthetic procedure that establishes meaning in the very act of creating paint seame, rescuing the indexicality of children's drawing, and its meaning as a language autonomous. In the second section, moving on to the analysis of children's work from the symbolic aesthetic, children's art as a symbolic language refers to a signifier that is not necessarily conscious; presenting something that is not, materialized through painting, as a symbolic inscription vehicle. In the last section. opting for an analysis of children's art from the expanded aesthetic, where to from the aisthesis, art is everything and for everyone, including the art of children and youth.

Keywords: Education - Aesthetics - Children - Drawings - Child.

\footnotetext{
* Doctoranda en Educación de la Universidad de Baja California (México). Magister en Historia del Arte Universidad de Antioquia (UDEA). Licenciada en Educación Artes Plásticas UDEA. Maestra en Artes Plásticas UDEA. Docente de la Licenciatura en Artes Plásticas UDEA. Autora del libro Desarrollo Artístico de Niño. Artista Plástica y Audiovisual. Miembro del grupo de interés pedagógico: Educación Artística, Cultura, Infancia y Adolescencia, de la Facultad de Artes UDEA.
} 
Revista de la Escuela de Ciencias de la educación, año 15, nRo. 14, vol. 2, JUlio a diciembre de 2019. PÁginas 71-80. ISSN 1851-6297 (DESDE DIECIEMBRE DE 2006 A DICIEMBRE DE 2017). ISSN 2362-3349 (EN LínEA). TRAS LAS HUELLAS DEL ARTE INFANTIL. MARGARITA MARIA ZAPATA GUTIÉRREZ.

\section{Introducción}

Un horizonte antropológico no es un límite; por el contario tiene como fin la expansión de la experiencia, que, en las ciencias, a finales del siglo XIX, trazaría una vía metodológica para acceder a la observación de la humanidad en sus orígenes, lo que ayudaría a refundar las bases de las eternas verdades a priori, ahora relativas y humanas.

Pero ¿cuáles son las concepciones estéticas del arte infantil en este horizonte? Esta pregunta, necesariamente nos lleva a explorar el origen antropológico del arte, donde fungen el arte y su trasmisión, como continuum en la experiencia del hombre prehistórico, en donde expresión y mano toman forma a través de la inscripción y su transferencia cultural. Huellas, trazos, que encarnan sentido; "formas simbólicas" que crean mundo, tejiendo universos culturales y singulares diversos. Grafías, índices, signos, que como unidad antropológica configurarán un nuevo lenguaje de signos expresivos llamado "arte", distinto y autónomo del lenguaje como lengua. Así, el arte en su retorno al origen, es capacidad innata de todas las personas, incluidos niños, pre, y adolescentes.

El arte infantil, es pues un lenguaje expresivo que, en su praxis cultural, ha sido condicionado por el sistema, las concepciones, prácticas y discursos del arte y la pedagogía, siendo en consecuencia, privilegio de varones, altas elites y dotados hasta el siglo XIX, época en donde el dibujo como enseñanza de las artes plásticas, empezará a formar parte de la educación popular, a través de la Escuela Nueva, tras el impulso de estudios sobre el niño, su dibujo y su desarrollo artístico que se venían generando, y que aportaron progresivamente a la constitución de un nuevo campo de conceptualización, saber, y análisis de la enseñanza de las artes. Sin embargo, a pesar del auge del estudio del arte infantil, desde la psicología, la pedagogía y más contemporáneamente la semiología, es evidente que, aún en el siglo XXI, es un terreno de análisis olvidado en el ámbito de la filosofía estética.

Este artículo es un enfoque entre otros posibles que, apoyado en la "transducción" como método interpretativo, elabora una transferencia de concepciones filosóficas de la estética contemporánea hacia el arte infantil, en cuyas singularidades deviene sentido como arte. Esto supone desarmar las teorías, extraer significantes, y ponerlos a resignificar en el análisis estético del arte de los niños, pre y adolescentes, específicamente enfocándonos en la expresión gráfico plástica.

No necesariamente en el orden de estas ideas, en el primer apartado, analizamos el Horizonte del arte infantil como lenguaje semiótico, apoyados por la transducción de concepciones de autores como Salabert (2003), Pierce (1987), Simón Marchan Fiz (1987), y Montoya (2008). En el Segundo apartado Horizonte del arte infantil como lenguaje simbólico, se retoman y recontextualizan, los conceptos de Saussure (2008), Cassirer (1945), Pardo (1992), y Gadamer (1991) entre otros. En el último apartado: La Estética Expandida como horizonte estético del arte infantil, nos guiamos especialmente por Jairo Montoya, filósofo que plantea la concepción de las estéticas: Restringida, Imbricada, Expandida, Semiótica y Simbólica, como nuevos ámbitos de recontextualización y reinterpretación de la filosófica estética a partir del giro lingüístico. Ámbitos entre los cuales se fundamenta nuestra perspectiva estética del arte infantil.

\section{Horizonte del arte infantil como lenguaje semiótico}

La Estética Semiótica, es un análisis estético, ubicado en un ámbito de interpretación del arte, como lenguaje de signos expresivos (índices, rastros, manchas...) que es autónomo del lenguaje como lengua, reinterpretando las teorías de la semiótica y la semiología, desde las cuales se puede resignificar además el arte de los niños, hasta ahora objeto de interrogación de pedagogos, artistas y psicólogos. La Estética Semiótica, parte de la concepción de estética como expresión de la sensibilidad, o aisthesis, y el arte es una manifestación humana innata desde la infancia. Desde allí, el arte infantil, constituye un lenguaje expresivo, cuyos signos artísticos (huellas, grafos, colores, etc.) conservan la aisthesis como unidad antropológica; y la diversidad de significantes que despliega como lenguaje expresivo, es decodificable e interpretable, gracias a su polisemia como signo.

Sin embargo, para lograr transitar y comprender esta interpretación, hay que viajar sin la vieja tradición estética, restringida al gran arte, las grandes obras y los grandes artistas, que renunciaron a la aisthesis, en búsqueda de un significado históricamente trascendente. Alivianados de la carga de su hegemonía, adentrémonos en la evolución biológica propuesta por Darwin, que planteó un nuevo paradigma que paulatinamente posibilitó nuevas lecturas en todos los campos de las ciencias humanas en el siglo XIX. Uno de estos caminos lo abrió Leroi Gourhan (1971), cuando descubrió la sorprendente evolución de la cara (en expresión y lenguaje) y de la mano (en útil y oficio), resultado de los cambios de percepción de los homínidos al ponerse de pie, desarrollar un cerebro complejo y desplazar el olfato y el gusto, por la vista y el oído, mudando a una mano prensil que elaboró herramientas, impulsando a la humanidad más allá del horizonte del suelo. 
Revista de la Escuela de Ciencias de la educación, año 15, nRo. 14, vol. 2, Julio a diciembre de 2019. PÁginas 71-80. ISSN 1851-6297 (DESDE DIECIEMBRE DE 2006 A DICIEMBRE DE 2017). ISSN 2362-3349 (EN LínEA). TRAS LAS HUELLAS DEL ARTE INFANTIL. MARGARITA MARIA ZAPATA GUTIÉRREZ.

Según Ceballos (2006), la propuesta de Gourhan, se basa en la evolución mental, asociada a lo social y el lenguaje, en tanto que al erguirse, el hombre privilegia la vista y el oído como órganos que se conectan con lo externo (ver, escuchar, percibir, pensar) sobre el gusto y el olfato como órganos internos que se conectan al interior junto con la mano. La mano se especializa dejando su función de desplazamiento y aprehensión, hallando la función útil (hacer, objeto) y la cara la función expresión (expresión, lenguaje, pensamiento,). La mano dará origen al sistema técnico y la cara al sistema verbal. De acuerdo a Ceballos, todo ello unido a la transformación del lenguaje organizando sonidos, gestos expresivos, darán en consecuencia la posibilidad de concebir símbolos también expresivos, y su transformación en comunicación gráfica. Los instrumentos de simbolización (mano, cuerpo, cara) y los de lectura simbólica (oídos, ojos, gusto, tacto, olfato) dan origen a una lectura totalizante que llamaremos estética, que se configura desde la relación evolutiva entre mano-cara, y útil-lenguaje.

Tal revisión filogenética y de la percepción sensorial como fuente primordial de la expresión humana, colocaron a la estética en el horizonte antropológico desde donde todas las formas de sensibilidad estética como capacidad inherente del hombre, están al mismo nivel y lugar, hasta ahora reservado al arte. Esta visión unida a los estudios de Saussure (2008), cuyo encuentro de los elementales del lenguaje en la base antropológica del hombre y su fisiología, pusieron de relieve la importancia de la cultura en la significación del lenguaje y del arte. Tal idea la encontramos en el concepto de Dutton:

...el ámbito de las lenguas naturales se parece al campo del arte cuando se considera en su vertiente intercultural: ambos muestran un intercambio entre las estructuras profundas innatas y los mecanismos de la vida emocional, por un lado y un vasto océano de material cultural condicionado por la historia (Dutton, 2010, p. 51).

Abierto pues este horizonte estético, no hay un arte por encima del otro, y todas sus prácticas son manifestaciones estéticas, que coexisten con otras formas de exterioridad. Desde esta perspectiva, el arte no se reduce a estilos, expandiéndose a todas las expresiones artísticas, incluyendo aquellas en donde los límites entre el objeto y la realidad se han borrado, fragmentado o tensionado, y también aquellas en donde el artista busca la referencialidad del objeto; además de otras en donde la expresión se ha amalgamado con sus formas de contenido, porque "el signo icónico no se reduce simplemente a una imagen o a la realidad, ni el iconismo visual es un dispositivo para la ilusión óptica" (Salabert, 2003, s/p).

En este sentido, en la comprensión semiótica del arte de los niños, el signo gráfico, como indicaría Salabert, respecto al signo pictórico "está determinada por el trabajo de producirlos" (Salabert, 2003, s/p). Mediante el acto de exteriorización, la pintura de los niños es un cuerpo de inscripciones, en donde la tríada de referentes sígnicos propuestos por Pierce (1987), convergen: tanto el representamen (referencia al medio), el objeto (referencia al objeto) como el interpretante, (referencia a la conciencia interpretante). El estilo de la pintura infantil como aisthesis, responde al doble propósito de referencialidad y expresión, donde la preeminencia de su indexicalidad, o huella de su gestualidad, no borra ni suprime la tríada referencial del signo que propone Pierce, porque el niño accede a la realidad, extrae sus formas, cualidades y posibilidades (representamen) a partir de objetos o eventos (objeto), y la materia gráfica inscrita, es interpretable desde la psicología, la pedagogía, la estética, o el gusto personal (consciencia interpretante).

Pero además la construcción semiótica de los signos del arte infantil es resultado de la exegesis, es decir, de sacar afuera el interior y plasmarlo sobre una superficie de inscripción a través de signos plásticos como registro y huella indexical de un ser sensible, capaz de comunicarse con un verdadero lenguaje por la imagen. Sin embargo, según investigaciones previas (Zapata 2006, 2007, 2009, 2013) (1), tampoco puede desconocerse que la aisthesis artística como condición innata, depende de condiciones fisiológicas universales (filogenéticas) e individuales (ontogenéticas y genéticas) y de condiciones psicoafectivas y socioculturales, como estímulos del ambiente que condicionan el desarrollo artístico del niño y sus formas de expresión.

El análisis estético del arte infantil debe nutrirse de la investigación o el estudio de estas teorías; el arte infantil no se sostiene como tal desde concepciones estéticas y críticas restringidas al gran arte en cuanto a su forma, contenido o estilo; si bien el niño tiene estilo, éste es individual y subjetivo y no obedece a ninguna convención, moda, o tendencia. "En una obra el estilo es consecuencia de una subjetividad individuadora que se afirma en la expresión y provoca su génesis de sentido" (Salabert, 2003, p. 14) "un estilo individuador, supone singularidad o diferencia" (Salabert, 2003, p. 30) "Cuando la expresión es personal nos proporciona un lenguaje que es tanto más eficaz cuanto más se afirma a sí mismo - en cuyo momento, sin embargo, ya es estilo" (Salabert, 2003, p. 11).

Si se estudian las etapas de desarrollo artístico, se puede comprender, por ejemplo, que el dibujo infantil inicia con una etapa abstracta, expresiva y sin contenido referencial explícito. Sin embargo, esto no quiere decir que, en la baja iconicidad del dibujo del niño pequeñito, no exista un proceso de representación interna-externa, como tampoco desaparece en la obra de Kandinsky o Pollock. El hombre es el único animal que, desde la más tierna infancia, es capaz de espontáneamente transformar una idea en grafía. Los signos 
Revista de la Escuela de Ciencias de la educación, año 15, nRo. 14, vol. 2, JUlio a diciembre de 2019. PÁginas 71-80. ISSN 1851-6297 (DESDE DIECIEMBRE DE 2006 A DICIEMBRE DE 2017). ISSN 2362-3349 (EN LínEA). TRAS LAS HUELLAS DEL ARTE INFANTIL. MARGARITA MARIA ZAPATA GUTIÉRREZ.

gráficos del niño sustituyen las representaciones internas y las reconstruyen como iconos, índices o huellas que virtualizan sus ideas, independientemente de su semejanza con el objeto, o de su bajo nivel de

consciencia, transformándolas en símbolo gráfico al usarlos como tal, dándoles así un valor simbólico, comunicativo y expresivo, que si bien no se da por autonomía artística o por convención de estilo como el Arte Abstracto de Kandinsky, o el Expresionismo Abstracto de Pollock, se da como expresión interpretante del niño.

En términos de Salabert, la iconicidad de la obra está vinculada a procesos prioceptivos, es decir externos, mientras que la indicialidad pictórica está ligada a la expresión y la percepción del propio cuerpo en el acto mismo de pintar. "Así el cuerpo de la expresión es un territorio, el lugar espacio-temporal de una apropiación. Y decir forma con referencia a este cuerpo equivale a decir huella, signo de una expresión" (Salabert, 2003, p. 167) mientras que la referencialidad nos guía por el camino del iconismo de lo "superficial». Por ello, la puesta en obra del arte infantil es "es todo un juego entre un proceder semiótico y otro estético" (Salabert, 2003, p. 169), donde confluyen lenguaje y arte como construcciones semióticas que compromete realidades individualizadas, a la vez que procesos socio-culturales. En este proceso de construcción semiótica de la obra infantil, convergen lo signos de la realidad codificada en distintos niveles de consciencia según la edad, según plantea Matthews (2002), a través de imágenes pictóricas, a las que Salabert denomina hipoíconos. El dibujo del niño constituye entonces la virtualización del mundo, materializada a través signos pictóricos.

Para Salabert, el artista representa en el cuadro una substancia real (cuerpo eidético/objeto de la expresión) que abarca la representación de entidades del mundo desde un alto grado de iconicidad, hasta el formalismo no figurativo (Salabert, 2003). Por ello, la obra del niño de aproximadamente dos años, representa una "materia textural", una grafía espontánea, huellas, índices, en fin; un trazo anicónico (bajo grado de referencialidad) que es signo pictórico (abstracto); un cuerpo de expresión, aunque no remita a ningún objeto. En esta etapa del dibujo, identificada generalmente por los autores como garabato desordenado, 0 informe (sin forma/sin orden) que denominaremos por su carácter textural como etapa expresiva (no figurativa o anicónica), en donde los signos presentan una forma de contenido, y una forma de expresión disueltas en el mismo plano; no hay distinción de cualquier sustancia, dado su falta de referencialidad.

Sin embargo, en términos de Salabert, podemos decir, que el signo pictórico infantil cuando es una forma de expresión ajena a la significación, no es un signo: es una materia textural presente, es decir juna cosa real!

Parece remitir a sí mismo rechazando la referencialidad, la no-figuración quizá se pueda hablar de una forma de expresión vinculada a una forma de contenido, que deberíamos declarar ajena a la significación, [...]. Esta es una posibilidad. Aunque tal vez, si extremamos aún más el asunto, podríamos hablar de una significación autónoma (una materia textural presente) y por tanto extraña a todo contenido. Esto, finalmente, supondría la paradoja de tener que reconocer que no estamos ante un signo sino ante una cosa real en función de ostensividad...(Salabert, 2003, p. 169).

El niño pequeñito expresa, no representa, presenta, materializa, y "crea" una imagen real, en tanto que no imita, ni tiene la intención de representar, presentando algo nuevo que de hecho no existía; porque sus primeros dibujos, no tienen un significado poético en sentido estricto. No muy lejos de estos primeros trazos indexicales, el bebé descubre que a partir del registro de la huella del lápiz sobre una superficie de inscripción puede crear imágenes, dando un salto cognitivo que lo preparará para la representación de ideas mentales, tanto referidas al objeto o simbólicas (pintura) como no referidas al objeto o notacionales (escritura, matemática, música).

En la representación pictórica de niños y jóvenes predominará por la naturaleza paulatina de su desarrollo cognitivo, el plano de la expresión, sobre el plano de contenido, hasta llegar a invertirlos y conjugarlos. El plano de expresión para Salabert consisten en "La expresión personal en el sentido físico de la grafía o la texturalidad, resultado de proyectar el sujeto en un obra su dimensión somática, mediante formas que devienen significativas" (Salabert, 2003, p. 195); características del dibujo infantil que han llevado a la psicología a interpretar la personalidad, los miedos y la inteligencia del niño. No obstante, en oposición al concepto de Salabert, en su análisis clínico, el psicólogo no se interesa en la pintura como arte, buscando contenidos psíquicos en los signos pictóricos, transformados en indicios cognitivos, o marcas simbólicas, síntomas, traumas y fantasmas, somatizados a través de la pintura o el dibujo.

Otra perspectiva pedagógica desde la semiótica, es la propuesta por Martínez (2002), que indica:

Si estamos ante un lenguaje, ante un sistema organizado de signos y símbolos, habrá que intentar comprenderlo como tal. El modelo semiótico permite una aproximación fiable al 


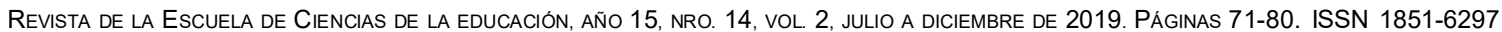
(DESDE DIECIEMBRE DE 2006 A DICIEMBRE DE 2017). ISSN 2362-3349 (EN LínEA). TRAS LAS HUELLAS DEL ARTE INFANTIL. MARGARITA MARIA ZAPATA GUTIÉRREZ.

fenómeno de las construcciones iconográficas autónomas en la infancia, atendiendo a sus funciones básicas (Martínez, 2002, s/p).

La tesis de Martínez, sin ser estética, propone aplicar un modelo lingüístico a la obra infantil, para encontrar su sentido cultural-convencional, codificando las estructuras visuales del dibujo, a partir de la sintáctica y la semántica; es decir, el significado y el sentido, encontrando imágenes iconográficas con diferentes niveles de significación simbólico-cultural, nexos entre sintaxis visuales, y nexos semánticos entre contenidos.

EI modelo aplica las cualidades de la lengua, al lenguaje pictórico infantil, concebido como cadenas de signos, símbolos, metáforas y metalenguajes, con significantes culturales. En contraste, a la concepción expuesta basados en Salabert, en el modelo de Martínez, las primeras grafías pierden todo significado dada su aniconicidad y su carencia de referentes semánticos. Además, las manifestaciones artísticas de los niños no se reducen a los procesos semióticos. En los procesos asemióticos internos que propone la semiótica como lenguaje independiente de la lengua, los signos son irreductibles a la convención cultural, emergiendo como rastros, huellas y marcajes psíquicos casi siempre inconscientes y ocultos, enigmas que los psicólogos han dado en llamar fantasmas o alegorías inconscientes.

Por otra parte, los signos artísticos transformados en sintaxis, semántica y metáforas visuales, necesitan del lenguaje para ser codificables y decodificables. Es decir, un arte por el lenguaje. Correlato, cuya racionalidad, desconoce su aisthesis, su indicialidad, y su sentido como experiencia estética, incapaz de interpretar su singularidad como expresión. Apoyamos ésta idea transduciendo las concepciones de Javier Domínguez, Simón Marchan Fiz, y Montoya:

la orientación de ésta metodología, apoyada en criterios de un pensamiento cientificista y por tanto en procedimientos de interpretación reglamentable y verificable, se estrelló ante la característica más ostensible de las obras de arte, a saber, su no univocidad, reflejada -según el caso- en su polisemia, su equivocidad o precariedad comunicativa" (Domínguez, 2003, p. 189) Volviendo al papel inter-mediador [...] -significante y significado; materia y forma, según el caso- y su consecuente adecuación -obviamente pre-supuesta- vuelven a fundamentar el despliegue metafórico como rasgo fundamental tanto del arte como del lenguaje" (Montoya Gómez, 2008, pp., 190-191) atentando contra "la condición matérica de la obra, a la especificidad del oficio y a la reivindicación del ejercicio "escritural" del arte mismo" (Marchán Fiz, 1987, pp. 190-191), hay que: “...prestarle atención a esa característica de la obra de comunicar y mediar sentido por sí misma. (Domínguez, 2003, pp. 190-191).

Como la obra adulta, la obra infantil, es un lenguaje gráfico capaz de comunicar sentido por sí misma, expresando sentidos que la lengua no logra expresar o penetrar. La inmanencia de su expresión y contenido no pueden separarse son irreductibles -si bien en términos lingüísticos- por su polisemia, pueden examinarse teóricamente por separado, como caras de un mismo signo; de allí las diferencias conceptuales que es capaz de levantar como sentido. Afirmamos esta concepción en Arnheim (1989), que, desmitificando el lenguaje como sinónimo de pensamiento, atribuye a la percepción, la conjunción entre entorno (materia sígnica-simbólica) y pensamiento (abstracción simbólica).

Para Arnheim, el pensamiento: "opera a través de las cosas a las que se refiere el lenguaje, referentes que en sí mismos no son verbales sino perceptivos" (Arnheim, 1989., p. 145). Desde ésta perspectiva, "toda percepción es simbólica" (Arnheim, 1989, p. 248) en la medida que signos visuales, sonoros y hápticos, son materia visible, audible, degustable, olfateable o palpable, que desencadenan procesos sinápticos en la red de circuitos neuronales del sistema nervioso (2) en donde toda materia perceptible es transformada en imagen, sonido, sabor, olor, sensación; propiciando emociones, pensamientos, conexiones semióticas y asemióticas que producen relaciones simbólicas nuevas, ideas, o refuerzan la memoria, y que exteriorizadas por medio de representaciones gráficas notacionales o simbólicas, el cuerpo, o el habla, salen de adentro hacia afuera como materia simbólica o semiótica, entre otras formas de manifestarnos como humanos.

El arte de los niños no es un espejo del lenguaje; es un lenguaje autónomo con signos que se conectan con su audiencia. De tal modo que, sin ser complejos como los signos artísticos del arte adulto, y el gran arte, son potentes y capaces de transmitir sentido sin intermediación de la lengua. Es materia indexical, huella, registro, virtual que sincretiza el desarrollo y las experiencias vitales a través de una superficie de inscripción.

\section{Horizonte del arte infantil como lenguaje simbólico}

La Estética Simbólica, reconstruye la noción de arte como lenguaje simbólico, inscripción simbólica, que desde Saussure (2008), Levy Strauss (1995), Cassirer (1945), y otros, empieza a configurarse. Desde esta noción el arte infantil, puede entenderse como una huella instauradora de sentido. El estructuralismo, demostró que el arte como expresión simbólica ya no remite a significados unívocos, expandiéndose a la 
ReVista de la Escuela de Ciencias de la educación, año 15, nRo. 14, vol. 2, JULIO a diciembre de 2019. PÁGINAS 71-80. ISSN 1851-6297 (DESDE DIECIEMBRE DE 2006 A DICIEMBRE DE 2017). ISSN 2362-3349 (EN LínEA). TRAS LAS HUELLAS DEL ARTE INFANTIL. MARGARITA MARIA ZAPATA GUTIÉRREZ.

noción de sentido, y a lo simbólico como el campo interno/externo en que se constituye, en donde el arte como lenguaje simbólico de signos plásticos, es posible de decodificar en múltiples sentidos, restableciendo el valor de los medios expresivos por sobre los contenidos y las formas útiles.

De acuerdo a Pardo (1992), el estructuralismo rompe con la tradición de un lenguaje (o unos lenguajes) donde el significado precede al signo, y está centrado en el dominio de la totalidad de la lengua sobre sus partes, atadas a unas convenciones fijas. Saussure (2008), encuentra otra estructura simple, capaz de cobijar a todas las lenguas, donde "los significantes se -descomponen- en elementos insignificantes" (Pardo, 1992, p. 21), contrayendo el lenguaje en simples fonemas (y morfemas) que no tienen significado ni valor propio, encontrando el valor perdido del signo sobre el significado, valor esencial para extraer todo sentido en la construcción simbólica del lenguaje humano. Se trata, dice Pardo, de instaurar la noción de sentido, de de-construir, disolver, desde el signo para ubicamos en el espacio de lo simbólico, porque los signos no tienen sentido, les damos sentido.

Pareciera entonces aceptable dar por sentado, el -sin sentido estético- de las primeras grafías del bebé (3) por convención "sin forma ni contenido". Sin embargo, su "significado ya está presente como un todo" (José Luis Pardo, 1992, p. 26). Atendiendo a que, los signos no tienen sentido, les damos sentido, el sentido estético de las primeras grafías infantiles, no existe justamente porque no se lo hemos dado. Porque "Un símbolo, se autodestruye si carece de un portador colectivo" (Debray, 2001, pp. 13-52). De allí la persistencia de su sin sentido estético, y su efectividad simbólica en el campo de la psicología. Dicho de otra forma: el simbolismo de la obra infantil está tanto dentro como fuera de ella, en la cultura y el individuo que la percibe.

De tal modo que, si como sus perceptores atendemos a la totalidad visual como el significado establecido (arte sin sentido) por encima de los significantes que expresa (signos plásticos), es imposible su simbolismo estético, aunque, sea simbólico en la perspectiva del psicólogo. El niño pequeñito no declara un contenido: lo presenta, lo instaura, y no es convencional. El discurso estético restringido al arte, no lo aprehende, no lo alcanza y lo invalida como Platón al arte, como copia de la idea de la idea. De tal modo que la simplicidad universal de sus unidades sígnicas no tiene significado estético como arte, en ninguna teoría estética conocida en ésta investigación, a excepción de la expuesta por Arnheim (1989) en su capítulo El Desarrollo, en Arte y percepción visual, donde considera que el arte de los niños es la más pura forma de arte.

Apegándonos a Pardo, hay que acudir a la búsqueda del valor perdido del signo [plástico] de la grafía infantil, como valor esencial para extraer el sentido estético de su construcción simbólica, y devolverlo al terreno de expresión al que pertenece, que invita a "discernir lo simbólico del símbolo, y desglosar el sentido de su órbita semiótica" (Debray, 2010.). Habrá que desglosarlo en la misma tradición estética, donde "la experiencia del arte viene dada por el modo en que desvincula la imaginación de su propósito práctico, liberándola, tal como enseña Kant, de las limitaciones de la lógica y de la comprensión racional" (Dutton, 2010, p. 89), porque "el arte no quiere instruir, sino conmover y la conducta adecuada frente a él no es la actitud de la razón, sino la del sentimiento" (Hauser, 2006, p. 567); "la obra nos habla como obra, y no como portadora de un mensaje" (Alvarado, s/f., p. 86).

No obstante, la obra infantil, comunica: "en ella misma puede encontrarse lo que ella tenga que decir" (Gadamer, 1991, s/p). Pero a diferencia del gran arte, no responde a estilos, tendencias, mercados, o filosofías; se soporta por sí misma en un campo simbólico que le pertenece: la pintura infantil, cuyo lenguaje es universal, aisthesis, vehículo de inscripción, cuyos signos nos arrojan al ámbito simbólico, es decir a la huella instauradora de sentido, donde no hay un arte por encima de otro, y no hay evolución sino transformación.

Por ello en cada fase del dibujo infantil, la expresión gráfica como aisthesis, tiene el mismo sentido: la exteriorización de la sensibilidad a través de una superficie de inscripción, en donde huellas, índices, trazas, gestos, íconos, signos, símbolos, texturas, colores, iconos, etc., son impronta de sensibilidad, y, "ese acto de realizar grafías, sean palabras o trazos, constituyen la marca, la huella de lo humano" (Montoya Gómez, 2008, p. 193). La grafía infantil es una habilidad innata, donde el niño materializa algo, que exhibe lo que realmente ya no está. Para Montoya:

Sin esa capacidad de 'traer a la presencia algo que no está presente' sin ese 'poner de manifiesto algo que no está' no hay en rigor grafía, porque no hay desterritorialización en ese espacio de constitución de la experiencia humana (Montoya Gómez, 2008, p. 82).

La huella como instauradora de sentido en el arte de los niños, es un acto simbólico en sí mismo que nada tiene que ver con el menor o mayor grado de iconicidad (4). Como antes se indica, el niño pequeño crea, no reproduce; presenta no representa; si bien progresivamente al crecer, carga la obra de contenidos y encarnaciones simbólicas más complejas e intencionadas. Para Arnheim, "aún la línea más simple expresa 
ReVista de la Escuela de Ciencias de la educación, año 15, nRo. 14, vol. 2, JULIO A diCiembre de 2019. PÁGINAS 71-80. ISSN 1851-6297 (DESDE DIECIEMBRE DE 2006 A DICIEMBRE DE 2017). ISSN 2362-3349 (EN LínEA). TRAS LAS HUELLAS DEL ARTE INFANTIL. MARGARITA MARIA ZAPATA GUTIÉRREZ.

un significado visible y por lo tanto es simbólica. No ofrece abstracciones intelectuales porque no hay nada más concreto que el color, la forma y el movimiento" (Arnheim, 1962, p. 347).

Por ello, la expresión simbólica del niño, a través del dibujo y la pintura, no está limitada por los niveles de consciencia o inconsciencia propias de su desarrollo, porque "la esencia de lo simbólico consiste precisamente en que no está referido a un fin con un significado que haya de alcanzarse intelectualmente, sino que detenta en sí su significado" (Gadamer, 1991, p. 95) "Cifrar la creencia en el 'logos' [...] implica como presupuesto la determinación del ser de las cosas como presencia, y la consiguiente exclusión de la grafía y del trazo a la exterioridad del sentido" (Montoya Gómez, 2008, p. 198) Dicho de otra manera; la función escritural del arte infantil trae a la presencia lo imaginado, pensado, deseado, creado en su interior, que no necesariamente implica lo conscientemente fijado, porque el arte como el lenguaje, por sí solo no es capaz de contener el sentido de algo por sí mismo; como el olor degustable de una imagen sonora.

Los símbolos: "transmiten siempre representaciones vivas -en el sentido de traer a la presencia-"(Jiménez, 2003; Montoya Gómez, 2008, p. 65). La lengua requiere para ello, por ejemplo, desmaterializar el sonido a través de la representación interna/externa de signos gráficos notacionales (sonido-imagen-grafo), el arte infantil desmaterializa la realidad interna/externa a través de signos plásticos (color-textura-línea-forma., etc.) El arte infantil, como la razón y el lenguaje, no explica por sí mismo la sensación de lo salado o lo simple, lo hermoso o feo; el niño en su condición orgánica, psíquica e incluso étnica, y desde pequeño, le halla gusto y sentido; por ello en su obra no sólo exterioriza una escritura plástica, también las formas de interioridad que le anteceden: no es puramente espontáneo.

Según Salabert, "En la génesis de una pintura, [...] hay un proceder intencional, un que-hacer que sin embargo no tiene por qué ser idea clara, ni tan siquiera una determinación consciente" (Salabert, 2003, p. 55), pudiendo proceder de una experiencia exclusivamente emocional:

Cuando una idea se resuelve en un acto de «expresión» sea estético o no lo sea, es porque un acto anterior, alguna experiencia cuya naturaleza puede ser exclusivamente emocional, ha determinado una intencionalidad que entra en acción y elabora unos signos (Salabert, 2003, p. $56)$.

Por tanto, la expresión simbólica del arte infantil, aunque no está cifrada en la convención, la exterioriza. El signo plástico como código estético, es la impronta, la marca, la huella sensible de un ser que deviene simbólico y crea mundo a través de la grafía. Pero, no es sólo un registro individual, también es inscripción simbólica de un colectivo y la demora de su desterritorialización, mediante el acto plástico creativo. Por ello a lo largo de las etapas de desarrollo artístico, el dibujo encarna la construcción progresiva de significaciones vívidas cada vez más complejas, que inician con la exploración del cuerpo como dispositivo simbólico (gesto-expresión), y consecutivamente abarcan la noción como individuo de una especie (figura), de un grupo, (familia), de un entorno cercano, (casa), de un territorio natural (naturaleza subjetiva) como significaciones "subjetivas" de la identidad, que serán desterritorializados por la racionalidad impuesta por la realidad objetiva (naturaleza objetiva) hasta problematizar el mundo (ideas-mundo) desterritorializando lo objetivo, para exteriorizar las concepciones del mundo. De tal modo que en un gesto que configura un trazo, un círculo que toma forma humana, hay significaciones; el niño emite y transmite inscripciones simbólicas que arroja al mundo como animal simbólico, encarnado a través de la obra, no sólo objetos visuales, también ideas de sí mismo y el mundo.

\section{La Estética Expandida como horizonte estético del arte infantil}

En el discurso de la Estética Expandida, la estética busca un horizonte de antropologización encontrando en la aisthesis, la expresión de la sensibilidad humana, en donde todos podemos manifestarnos, incluyendo los niños. Ceballos caracteriza el modelo de la siguiente forma:

Se entiende como campo expandido del arte, el movimiento iniciado al comenzar la segunda mitad del siglo XX, con sus raíces en las propuestas elaboradas por el artista francés Marcel Duchamp, (1887-1968), y el movimiento Dadá en los años1920/1930. Posteriormente, una sistematización más profunda del "campo expandido del arte" se logra en la década de los 70s, cuando se hizo clara la crisis de la modernidad y el arte proponía nuevos rumbos. Este campo de conocimiento aboga por un retorno a lo fundamental de la expresión en el arte y al abandono del academicismo que lo priva de libertad. Implica volver a las relaciones de la expresión y producciones artísticas, con los sentidos de la percepción del hombre: los lejanos visión y audición, y los cercanos, gusto tacto y olfato, expresados por el cuerpo y el movimiento (Ceballos Córdoba, 2006, pp. 179-180). 
ReVista de la Escuela de Ciencias de la educación, año 15, nRo. 14, vol. 2, JULIO a diciembre de 2019. PÁGINAS 71-80. ISSN 1851-6297 (DESDE DIECIEMBRE DE 2006 A DICIEMBRE DE 2017). ISSN 2362-3349 (EN LínEA). TRAS LAS HUELLAS DEL ARTE INFANTIL. MARGARITA MARIA ZAPATA GUTIÉRREZ.

En la Estética Expandida, se comprende que, la fisiología del hombre como unidad antropológica, arrastra una génesis filogenética y ontogenética, donde la sensibilidad como aisthesis fue clave en la constitución de la especie; así la aisthesis como unidad estética, arrasa con jerarquías y diferencias entre

culturas y artes, y el cuerpo dispositivo sensible y recipiente simbólico, también es materia plástica modificable por la cultura, que lo desnaturaliza y lo arroja a sus artificios. Para Montoya, esta es la "punta del 'ICEBERG de lo estético' que es donde 'el arte' tiene toda su fundamentación" (Montoya Gómez, 2008, p. 249).

En este horizonte expandido, el arte como expresión propia del hombre es una práctica donde colectivos e individuos, tienen sus propias formas de inscripción de la sensibilidad, que sitúan las prácticas artísticas en escenarios sociales y campos simbólicos distintos. La Estética Expandida, por tanto, libera la estética de su restricción al arte, pero no lo excluye, ni a sus grandes discursos, e incluye el arte de los niños, como práctica social, si bien no lo expresa ni lo incluye en sus teorías. Ésta propone en síntesis una expansión de la estética sin las viejas dicotomías entre sensibilidad y razón, porque "de la mano de la concepción dicotómica de la realidad, terminamos por proyectar en el arte los conceptos de forma y contenido" (Montoya Gómez, 2008, p. 212). Por lo mismo, la sensibilidad pura como antimonia, es una purificación:

La adscripción de la experiencia estética al dominio de lo "sensible" -la percepción y la sensibilidad incluidas- para comprender porqué también en la esfera de la experiencia artística hemos terminado por replicar esta visión dicotómica de la realidad [...] para explicar la experiencia artística es necesario limpiarla de toda materia que "contamine" sus formas puras, no importando que su resultado termine por ser una antinomia: la sensibilidad pura (Montoya Gómez, 2008, p. 212).

La sensibilidad pura en el arte, agota los medios pictóricos; la exclusión de lo figurativo lleva la función referencial a su exterminio práctico, y a la muerte del arte "tradicionalmente figurativo". El imperio de lo sensible, contradictoriamente anula el cuadro, saliéndose del marco hacia el espacio y los objetos, sustituyendo la realidad por la realidad misma; borrando el límite entre la realidad y su simulacro, una nueva mimesis que lo retorna al lenguaje, y a la razón del crítico como intermediarios de un espectáculo abstracto, lejos de la vida común, sometiendo al espectador al juicio del crítico o sucumbir a las formas insólitas de la obra.

En palabras de Montoya:

Formas, por una parte, significados por otra. Cuando la opción entre la razón y la sensibilidad adquirió los visos de una oposición entre dos formas de relacionarnos con las cosas, la razón de una actividad como el arte se vio también condenada a una perpetua justificación (Montoya Gómez, 2008, pp. 212-213).

Ambos extremos, aniquilan la naturaleza polisémica del arte, desconociendo que razón y percepción sensible operan en simultáneo: "percepción y pensamiento no pueden funcionar separadamente. Las capacidades comúnmente reconocidas al pensamiento -distinguir, comparar, elegir, etc.- operan en la percepción elemental; $y$, al mismo tiempo, todo pensamiento requiere una base sensorial" (Arnheim, 1989, p. 28). De allí que tanto sensibilidad como razón se conjugan en la experiencia estética del homo, desde la infancia; el recién nacido no es sólo pulsiones, emociones y reacciones autoplásticas primarias.

El significado de la obra infantil, para algunos, media pues entre antimonias estéticas: pura expresión sin contenido en la etapa inicial, y contenido sin expresión en la última, dando por sentado que la universalidad gráfica como fenómeno humano, equivale a que la obra infantil es inmadura, incompleta y fallida hasta no superar las etapas gráficas y alcanzar las formas y contenidos de la obra adulta. Sin embargo, en cada etapa, el arte infantil, es una potente forma de expresión. Reconocer sus singularidades y diferencias con el gran arte, es más sano que purificarlo. El arte tiene una historia donde gano su autonomía y reconocimiento como disciplina; y el artista plástico se ha ganado un estatus profesional; distinto de aquel, que siendo niño se reconoce como tal. Ambos artistas y artes coexisten en el horizonte de la Estética Expandida, que abraza además otras artes, y formas de expresión de la sensibilidad.

Es indudable que, aunque los niños no aspiran al mercado, la trascendencia, la crítica y el análisis estético de sus obras, el adeudo de la filosofía estética, con esta forma de expresión humana es evidenciable. Tenemos entonces la tarea de hacerlo, y construir un diálogo intercultural amplio, que visibilice el arte de los niños, introduciendo sentido en lo que hasta ahora ha sido invisibilizado por la tradición.

\section{Conclusiones}

A partir de un análisis expandido hacia un horizonte de antropologización del arte, encontramos en la aisthesis como unidad antropológica, una estética filosófica, que, desde variadas perspectivas, 
Revista de la Escuela de Ciencias de la educación, año 15, NRo. 14, vol. 2, Julio a diciembre de 2019. PÁginas 71-80. ISSN 1851-6297 (DESDE DIECIEMBRE DE 2006 A DICIEMBRE DE 2017). ISSN 2362-3349 (EN LíNEA). TRAS LAS HUELLAS DEL ARTE INFANTIL. MARGARITA MARIA ZAPATA GUTIÉRREZ.

transgreden la noción de la estética restringida al arte como único portador de la sensibilidad humana, trasformando la sensibilidad estética y artística en un derecho de todos y para todos, incluyendo el arte de los niños, pre y adolescentes.

Desde este horizonte, y en perspectiva de la Estética Semiótica, el arte infantil es un lenguaje expresivo de signos (gráficos, plásticos, artísticos, etc.) producidos en el mismo acto de crear, y dejar huella, registro e índice de la sensibilidad; sea de forma consciente o inconsciente, el niño exterioriza en el dibujo, significados más allá del lenguaje como lengua. Para un niño, la pintura es una experiencia vital, y como capacidad innata, se transforma y materializa de forma cada vez más consciente.

Desde la perspectiva de la Estética Simbólica, el arte es un lenguaje simbólico que deja impronta de algo que no está presente y que el artista materializa a través de una superficie de inscripción. El niño, como animal simbólico, es capaz de virtualizar y encarnar ideas en la pintura, de manera progresivamente compleja.

Desde el horizonte de la Estética Expandida, el arte es aisthesis, vehículo de la sensibilidad. Por eso las obras de los niños también son formas de exterioridad, a través de una superficie de inscripción, que encarna cuerpo y cultura, como lenguaje simbólico, semiótico, estético y artístico.

La obra infantil, en tanto, es libre de convenciones, no se reduce ni al signo, ni al símbolo, ni al lenguaje, ni a la razón; pero como el arte es interpretable por su naturaleza polisémica.

El arte de los niños, no responde a estilos, mercados, ni trascendencias. Sin embargo, hay que empezar a reflexionar la pintura infantil, también desde el discurso estético que amerita como expresión y como objeto de interés pedagógico. Sin embargo, cualquier interpretación estética del arte infantil, aunque puede ser diversa, sólo puede partir de lo que el mismo es.

\section{Notas Bibliográficas}

(1) "Como toda expresión gráfica, el ejercicio escritural del niño a través de los signos artísticos presentes en el dibujo o la pintura, es una habilidad universal adquirida por la especie en los procesos de transformación que separaron al hombre de su sustrato zoológico. Dicha condición innata de la grafía artística del niño, no inicia con la primera línea, o la primera figura como concluyen otros estudios; surge en la etapa intrauterina en donde se gestan los procesos genéticos, ontológicos, y filogenéticos, fijados en el ADN humano que le permiten desarrollarse como individuo sensible, entendiendo la sensibilidad como función integrada a un sistema orgánico y por tanto compuesta de todas sus partes, incluyendo la inteligencia. Esta nueva concepción [...] reivindica el valor del cuerpo como dispositivo privilegiado de la sensibilidad humana, porque sólo a través de él es posible devenir sensible, un cuerpo que también es superficie de inscripción simbólica y que como materia plástica es moldeado por los espacios que habita, tanto materiales como inmateriales. Territorios que como significaciones vívidas salen a flote en el dibujo infantil, representando los vínculos de pertenecía e identidad simbólica, y sus dominios individuales y colectivos que vehiculan valores y pautas de conocimiento en cada etapa gráfica, con distintos signos, íconos, y símbolos, que expresan territorializaciones sobre los espacios significados y simultáneamente las desterritorializaciones y reterritorializaciones que elabora con cada modificación de su mundo interno/externo". [...], y que se refleja de forma distinta en cada etapa de su dibujo:

(2) De 0 a 9 meses. Se desarrollan en el embrión como Cuerpo Orgánico, los procesos autoplásticos y haloplásticos cerebrales, además del oído y el tacto, que le permitirán desarrollar sus primeros intercambios sensibles con el mundo.

(3) De 0 a 2 años, el bebé se explora como Cuerpo Sensible, simbolizando a través de signos semióticos corporales, huellas, gestos e índices.

(4) De 2 a 4 años, el infante se descubre como Espécimen Humano, simbolizándolo a través de la figura humana diferenciada, distinguiendo entre ésta y otras especies a través de signos anatómicos.

(5) De 2 a 4 años, el infante se experimenta como Ser Humano miembro (central) de una familia (grupo), simbolizándolo en dibujos sobre la familia.

(6) De 4 a 6 años, el infante se sondea como Individuo habiente de un entorno grupal cercano simbolizándolo a través diferentes representaciones de la casa, incluyendo o no la naturaleza, a él mismo, y los miembros de la familia.

(7) De 4 a 6 años, el infante se explora como Ser Natural emplazado en la naturaleza simbolizándolo a través de una naturaleza subjetiva y humanizada.

(8) De 6 a 12 años, el niño se observa como Ser Racional anclado en una naturaleza objetiva, que simboliza a través de una naturaleza sujeta a las leyes físicas.

(9) De 12 a 14 años, el pre adolescente urbano se investiga como Sujeto Cultural, y como observador situado en un mundo artificial, simbolizándolo a través de la representación de señales convencionales y espacios sociales, generalmente urbanos.

(10) De 14 a 17 años, el adolescente se identifica como Hombre Pensante, creativo, estético, crítico y unidad disuelta en el mundo, expandiéndose al cosmos de su pensamiento, simbolizándolo a través de críticas sociales, éticas, morales, políticas, estéticas, etc. (Zapata, 2012, p. 64).

(11) Las sinapsis permiten a las neuronas del sistema nervioso central formar una red de circuitos neuronales. Son cruciales para los procesos biológicos que subyacen bajo la percepción y el pensamiento. También son el sistema mediante el cual el sistema nervioso conecta y controla todos los sistemas del cuerpo.

(12) Desde la psicología, el sentido de las primeras líneas expresivas del bebé está vinculado a procesos psíquicos, cuyo valor es el registro de la actividad mental y motora que empieza a manifestarse a través del dibujo, pero no tiene un carácter simbólico hasta la adquisición de la figura con nombre.

(13) Y aquí, el concepto se tropieza con la condición evolutiva del dibujo y el supuesto sin sentido estético de la simpleza de las líneas de un pequeño que ni siquiera puede hablar. Pero volteando la cara de este significado convencional, 
Revista de la Escuela de Ciencias de la educación, año 15, nRo. 14, vol. 2, JULIO a diCiembre de 2019. PÁGINAS 71-80. ISSN 1851-6297 (DESDE DIECIEMBRE DE 2006 A DICIEMBRE DE 2017). ISSN 2362-3349 (EN LínEA). TRAS LAS HUELLAS DEL ARTE INFANTIL. MARGARITA MARIA ZAPATA GUTIÉRREZ.

en las primeras líneas sin orden ni forma, hallamos desde la perspectiva de Arnheim, el más puro acto creativo: la traza del bebé no reproduce sino que produce, no recrea si no que crea, no imita sino que imagina... es decir, a diferencia de los animales adiestrados para el dibujo, el niño se explora a sí mismo como ser estético sensible, capaz de experimentar emociones a través del dibujo, al tiempo que traza signos gráficos (sin intención representativa), que simbólicamente expresan lo que en su interior va configurando del mundo.

\section{Referencias bibliográficas}

- Alvarado, C. F. (s. f.). Una estética expandida: Leroi-Gourhan y Gadamer de paleontologías y antropologías posibles. Recuperado de: http://es.scribd.com/doc/70607835/Estetica-Expandida

- Arnheim, R. (1962). "El Desarrollo. En Villa Ortiz, J. (Ed.), Mesera, R. (Trad).: Arte y Percepción Visual. Psicología de la Visión Creadora", Buenos Aires: Editorial Universitaria de Buenos Aires.

- $\quad$ Arnheim, R. (1989). Nuevos ensayos sobre psicología del arte (M. Cóndor Urduña, Trad.). Madrid: Alianza.

- Cassirer, E. (1945). Antropología filosófica: Introducción a una filosofía de la cultura. México: UNAM.

- Ceballos, H. (2006). Del arte de las sociedades a las sociedades del arte. Medellín: Universidad Pontificia Bolivariana.

- $\quad$ Debray, R. (2001). Introducción a La Mediología. Barcelona: Paidós.

- Domínguez, J. (2003). Cultura del juicio y experiencia del arte. Ensayos. Medellín: Editorial Universidad de Antioquia.

- Dutton, D. (2010). El instinto del arte. Belleza, placer y evolución humana (C. Font Paz, Trad.). Madrid: Editorial Paidós.

- Gadamer, H. G. (1991). La actualidad de lo bello. (A. Gómez Ramos, Trad.). Barcelona: Paidós.

- Hauser, A. (1962). Historia social de la literatura y el arte. Madrid: Guadarrama.

- Leroi Gourhan, A. (1971). El gesto y la palabra. Caracas: Publicaciones de la Universidad Central de Venezuela.

- Lévi-Strauss, C. (1995). Antropología estructural. Barcelona: Paidós.

- Marchán Fiz, S. (1987). La estética en la cultura moderna. Madrid: Alianza.

- Martínez García, M. L. (2002). "Indicadores socio-culturales en las representaciones gráficas de los niños". Arte, Individuo y Sociedad, pp. 103-109.

- Matthews, J. (2002). El arte de la infancia y la adolescencia. La construcción del significado arte. España: Paidós.

- Montoya Gómez, J. (2008). Explosiones lingüísticas, expansiones estéticas. Meedellín: Universidad Nacional de Colombia.

- Pardo, J. L. (1992). Las formas de la exterioridad. Editorial Pre-Textos.

- $\quad$ Pierce, Ch. (1987). Obra lógico semiótica. En: Sercovich, A. (Ed.). Madrid: Taurus.

- Salabert, P. (2003). El pensamiento visible. Facultad de Ciencias Humanas y Económicas. Medellín, Colombia: Universidad Nacional de Colombia.

- Saussure, F. (2008). Curso de lingüística general. Buenos Aires: Losada.

- Zapata, M. (2006). Síntesis y análisis relacional de algunas teorías sobre el desarrollo artístico del niño. Trabajo de grado. Licenciatura en Educación en Artes. Universidad de Antioquia. Facultad de Artes, Medellín.

- Zapata, M. (2009). Desarrollo Artístico del Niño. Perspectivas desde el análisis de teorías. Bogotá: Fondo Editorial Universidad Pedagógica Nacional.

- Zapata, M. (2007). "Una educación en artes para un desarrollo artístico del niño". Cuadernos de Arte y Pedagogía No 4. Tragaluz Editores s.a. Revista de la Facultad de Artes Universidad de Antioquia. Abril Junio, Medellín.

- Zapata, M. (2013). El fenómeno estético en las manifestaciones artísticas de los niños: expresión gráfica, cuerpo y marcaje. Trabajo de grado. Magíster en Historia del Arte - Artes Plásticas. Universidad de Antioquia. Facultad de Artes, Medellín. 